\title{
Hepatoprotective Effects of Red Beet Roots and Silymarin on Liver Toxicity Induced by Carbon Tetrachloride $\left(\mathrm{CCl}_{4}\right)$ in Rats
}

\author{
Omar NA, Abd Allah GA, El-Zeiny BM* \\ Department of Zoology, Faculty of Science, Damietta University
}

Received: 12 November 2014 / Accepted: 26 January 2015

* Corresponding author: (email: basmaelzeiny@ yahoo.com)

\begin{abstract}
The present work aims to investigate the potential protective effect of beet root juice and silymarin in liver toxicity and liver fibrosis induced by carbon tetrachloride $\left(\mathrm{CCl}_{4}\right)$ in rats. Sixty (60) male rats of Sprague Dawley strain each weighting $(145 \pm 5 \mathrm{~g})$ were randomly divided into 6 groups $(\mathrm{n}=10)$. After 8 weeks blood was collected to obtain serum to estimate enzymes (ALT, AST, GGT and ALP activity) and collagen IV levels. Liver tissue was removed for measuring hydroxyproline contents and histological examination using Haematoxylin, Eosin and Sirius red stains for fibrosis. The ALT, AST, GGT and ALP activity showed a highly significant increase $(<0.001)$ in $\mathrm{CCl}_{4}$ group. On the other hand, treatment with beet root juice and silymarin significantly $(<0.05)$ decreased than that of $\mathrm{CCl}_{4}$ group. Collagen IV levels and the hydroxyproline contents were significantly increased $(<0.001)$ in $\mathrm{CCl}_{4}$ group, while after treatment with silymarin, beet root juice or a combination of them there was a slightly decrease in collagen IV levels and the hydroxyproline contents than that of $\mathrm{CCl}_{4}$ group.

The histopathology of hepatic tissues at 8 weeks in $\mathrm{CCl}_{4}$ injected rats showed disturbed liver architecture with cloudy swelling of hepatocytes, fatty changes (degeneration) and portal fibrosis. While rats treated with beet root juice or silymarin showed slightly disturbed liver architecture. Further, examination for liver fibrosis using Sirius red stain in liver sections showed diffuse subsegmentations of the portal lobules in $\mathrm{CCl}_{4}$ intoxicated rats, while rats injected with $\mathrm{CCl}_{4}$ and treated with beet root juice and silymarin showed very minimal portal fibrosis.
\end{abstract}

Keywords: beet; $\mathrm{CCl}_{4}$; fibrosis; liver toxicity; silymarin

\section{Introduction}

The liver is the main organ of detoxification and is the site of metabolic conversion of endogenous and exogenous compounds. (Balistreri and Rej, 1994). Inflammation and fibrosis of the interlobular bile ducts in the portal tracts result in blockage of bilirubin drainage system as seen in sclerosing cholangitis and primary biliary cirrhosis. Blockage of interlobular and larger intrahepatic bile ducts is probably the major cause of jaundice in the space-occupying lesions of the liver that are produced in patients with other granulomatous disease, or primary and 
metastatic hepatic tumors (Whitby et al., 1988). Certain toxins cause injury to specific hepatocyte organelles. For example, following chronic alcohol ingestion, there may be predominantly mitochondrial damage eventuating in cell death; this sequence can be attributed to oxidation products of ethanol (e.g., acetaldhyde) (Moussavian et al., 1985).

Carbon tetrachloride $\left(\mathrm{CCl}_{4}\right)$ is one of the most used hepatic toxins for experimental induction of liver fibrosis and cirrhosis in laboratory animals (Zasshi, 2006; Tsuchiya et al., 2007). The mechanism of carbon tetrachloride -induced hepatotoxicity, especially necrosis and fatty liver, has long been a challenging subject of many researchers from various fields over the past 50 years. Even though, the mechanisms of tissue damage are different among chemicals and affected tissues, $\mathrm{CCl}_{4}$ has played a role as a key substance of tissue injury (Madrigal-Santillan et al., 2013). As a result, several important basic mechanisms of tissue damages have emerged; involving metabolic activation, reactive free radical metabolites, lipid peroxidation, covalent binding and disturbance of calcium homeostasis (Zasshi, 2006). Liver damage caused by $\mathrm{CCl}_{4}$ in mouse model system is closely to analogue of hepatotoxicity in human (Ko and Lim, 2006). In various forms of the liver diseases, serum levels of numerous cytosolic, mitochondrial, and membrane-associated enzymes are increased; the degree of elevation varies with the type of the disease. Subcellular distribution and mechanisms of release of the enzymes from liver tissue are currently regarded as most useful parameters in evaluation of the liver disease (Agarwal et al., 2006).

Red beet (BetaVulgaris $L$.) root is a vegetable characteristic of the Eastern and Central European diet, and is also used as a popular folk remedy for liver and kidney diseases, for stimulation of the immune and hematopoietic systems, and as a special diet in the treatment of cancer (Kanner et al., 2001; Kapadia et al., 2003). Besides, other active chemicals, beet root contain a unique class of water-soluble, nonphenolic antioxidants, the betalains, including two classes of compounds, red betacyanins (principally betanin) and yellow betaxanthines (Kanner et al., 2001). The antioxidant effects of betalains have been demonstrated mainly in various in vitro experiments (Kanner et al., 2001). To date, very few investigations on beetroot activity have been performed in vivo. In an early study by Kapadia et al. (1996) a commercial extract (betanin) was demonstrated to inhibit two-stage mouse lung and skin carcinogenesis. Also, Kapadia et al. (2003) investigated the cancer chemopreventive potential of betanin in three different experimental skin and liver tumor models in mice. They showed that coadministration of betanin with model carcinogens exhibited a chemopreventive effect on experimental carcinogenesis. The effect was evident as a significant reduction in tumor incidence, multiplicity, and delay in tumor latency period.

Szaefer et al. (2014) studied the effect of beet root juice on 7,12-dimethylbenz[a] anthracene (DMBA)-induced damage in liver and mammary gland of female Sprague-Dawley rats and concluded that the activities of all enzymes tested were enhanced in the animals treated with DMBA alone and in combination with beet root juice. The most significant changes in the level of the enzymes tested were observed for NAD (P) $\mathrm{H}$ : quinone oxidoreductase-1. In mammary gland, beet root juice induced the level of glutathione Stransferase enzyme involved in detoxification of DMBA active metabolites. The final effects of beet root juice are tissue specific and depend on the class of carcinogen (Szaefer et al., 2014).

Silymarin is a natural compound that is among the species derived from Silybum marianum. The plant contains at least seven flavolignans and the flavonoid taxifolin. The most important flavolignans present include silybin, silydianin, and silychristine. Silybin represents between $50 \%$ and $70 \%$ of the extract from silymarin. Silymarin has been used worldwide for many years as a complementary alternative medicine because of the beneficial effects associated with the treatment of hepatic diseases. The level of silymarin absorption is between $20 \%$ and 50\%. Silybin is the major compound of silymarin and limiting factors such as low solubility in water, low bioavailability, and poor intestinal absorption reduce its efficacy. New soluble silybin-derived biocompounds (silybinbis-hemisuccinate, $\quad \beta$-cyclodextrin complex, silybin-N-methyl-glucamine, silybin 11-O-phosphate, and silybinphosphatidylcholine) have thus been designed (Loguercio et al., 2013). Silymarin reduces the incidence of certain cancers (Deep et al., 2007). $\mathrm{Su}$ et al. (2013), used silymarin on nasopharyngeal carcinoma cells (NPC-TW01) and found an increase in Bcl-2 expression and a decrease in the activated caspase- 3 or apoptosisinducing factor (AIF) with low-dose $\left(80 \mu \mathrm{mol} \mathrm{l}^{-}\right.$ 
$\left.{ }^{1}\right)$ treatment. Silymarin has been reported to have antioxidant, immunomodulatory, anti-fibrotic, anti-proliferative, and antiviral properties. It also affects the synthesis of RNA and DNA. Furthermore, silymarin maintains the integrity of the hepatocyte membrane and impedes the entrance of toxic substances or xenobiotics. Due to its phenolic nature, it is capable of donating electrons to stabilize free radicals (FR) and reactive oxygen species (ROS). Silymarin also affects intracellular glutathione, which prevents lipoperoxidation of membranes (Karimi et al., 2011). Mazaheri et al. (2014) studied the coadministration of silymarin and deferoxamine against kidney, liver and heart iron deposition in male iron overload rat model. They concluded that there was a protective role of silymarin against iron dextran-induced iron deposition in male rats. Al-Rasheed et al. (2014) studied the potential impact of silymarin in combination with chlorogenic acid and/or melatonin in combating cardiomyopathy induced by $\mathrm{CCl}_{4}$. Their results proved that treatment with silymarin in combination with chlorogenic acid and melatonin was the most effective one in ameliorating the toxicity of $\mathrm{CCl}_{4}$ induced cardiac damage and this may support the use of this combination as an effective drug to treat cardiac damage induced by toxic agents. Rasool et al. (2014) investigated hepatoprotective effects of silymarin and glycyrrhizin in combination. They found that $\mathrm{CCl}_{4}$ induces hepatic damage and their findings indicated that silymarin and glycyrrhizin have hepatoprotective effects against oxidative stress of the liver.

The aim of the present study is to estimate the protective effects of beet root juice and silymarin on liver injury induced by $\mathrm{CCl}_{4}$ in male rats.

\section{Materials and methods}

Sixty male rats of Sprague Dawley strain weighing $(145 \pm 5 \mathrm{~g})$ were obtained from Nile center for experimental researches (Mansoura, Egypt). The rats were maintained under standard laboratory conditions in an air conditioned room and housed in stainless steel cages one per cage at temperature $22 \pm 3{ }^{\circ} \mathrm{C}$ and relative humidity 30 $70 \%$. The animal's diet was given ad libitum. Animals were acclimatized for one week prior to experiment.

All chemicals including, carbon tetrachloride $\left(\mathrm{CCl}_{4}\right)$, and Kits were fine grade chemicals purchased from local distributers (Sigma Co.) Cairo, Egypt. Silymarin was purchased from local pharmacy.

\section{Preparation of beet root juice}

Beet roots (Beta vulgaris $L$ ) were purchased from a local market at Mansoura, Egypt and the plants were authenticated by the Botany Department, Faculty of Agriculture, Mansoura University. The juice was prepared from chopped roots and filtered through stainless steel refinery.

\section{Experimental design}

After a period of adaptation on basal diet rats were divided into 6 groups: Group 1, Ten rats fed on basal diet and served as a negative control group. Group 2, Ten rats fed on basal diet and were given i.p dose of olive oil (vehicle group). Group 3, Ten rats given i.p dose of $\mathrm{CCl}_{4}$ in olive oil $\left(0.5 \mathrm{mg} \mathrm{Kg}^{-1}\right)$ twice a week to induce chronic damage in the liver, according to the method previously described by Theocharis et al. 2001. Group 4, Ten rats given an oral dose $8 \mathrm{ml} \mathrm{Kg}^{-}$ ${ }^{1}$ day $^{-1}$ of beet root juice and were injected with $\mathrm{CCl}_{4}$ in olive oil $\left(0.5 \mathrm{mg} \mathrm{Kg}^{-1}\right)$ twice a week. Group 5, Ten rats given an oral dose $\left(100 \mathrm{mg} \mathrm{Kg}^{-}\right.$ ${ }^{1}$ day $^{-1}$ ) of silymarin and were injected with $\mathrm{CCl}_{4}$ in olive oil $\left(0.5 \mathrm{mg} \mathrm{Kg}^{-1}\right)$ twice a week. Group 6, Ten rats given a combination of an oral dose (8 $\mathrm{ml} \mathrm{Kg}^{-1}$ day $\left.^{-1}\right)$ of beet root juice, i.p dose (100 mg $\mathrm{Kg}^{-1} \mathrm{day}^{-1}$ ) of silymarin and were injected with $\mathrm{CCl}_{4}$ in olive oil $\left(0.5 \mathrm{mg} \mathrm{Kg}^{-1}\right)$ twice a week. At the end of the experiment, the animals were fasted overnight, and then they were anaesthetized and sacrificed to obtain blood samples. Each blood sample was placed in dry clean centrifuge tube, and then centrifuged for 10 minutes at $3000 \mathrm{rpm}$ to separate the serum to determine ALT, AST, GGT and ALP.

\section{Determination of serum ALT and AST activities}

Alanine aminotransferase (ALT) and aspartate aminotransferase (AST) activities were assayed in serum samples by the method of Reitman and Frankel (1957) using a commercially available assay kit (Egyptian American Company for Laboratory Services, Egypt).

Determination of serum $\gamma$-Glutamyl Transferase (GGT) Activity

The activity of serum $\gamma$-Glutamyl Transferase 
was measured according to the method described by Vázquez-Medina et al. (2011).

\section{Determination of serum alkaline phosphatase (ALP) activity}

The activity of alkaline phosphatase in the serum was assayed by the method described by ELAaser and EL-Merzabani (1975).

\section{Determination of serum collagen IV activity}

The method is a modified form of that reported by Mandl et al. (1953) where collagenase is incubated for 5 hours with collagen. The extent of collagen breakdown was determined by using colorimetric ninhydrin method. The liberated amino acids were expressed as micrornoles of leucine per $100 \mathrm{ml}$ serum.

Liver tissues were collected for determination of hepatic hydroxyproline content and histopathological investigation by Haematoxylin, Eosin stain and Sirius red stain for liver fibrosis.

Determination of hepatic hydroxyproline content in liver

The content of hepatic hydroxyproline was determined by using the modified method of Laitinen et al. (1974).

\section{The Paraffin blocks preparation}

The hepatic tissues were prepared for light microscopy as described by Moussa et al. 1984. The fixative which has been used is $10 \%$ neutral buffered formalin $\mathrm{pH} 7$ (BDH, UK), after the fixation, the tissue is dehydrated by serial ascending concentration of alcohol (BDH, UK), and xylene (BDH, UK), then the tissue is embedded in paraffin wax (Sheruood, USA). The block of paraffin embedding tissue is cutting by microtome (West Germany) $5 \mu$ in thickness. The slide stained with Haematoxylin and Eosin for histopathological examination and Sirius red stain for fibrosis according to the methods of Junqueira et al. (1979).

\section{Image analysis}

Image analysis method was performed using Image J software, version $1.48 \mathrm{~d}$ (developed by Wayne Rasband, National Institutes of Health, Bethesda, Maryland, USA) (Rasband 1997-2014) and Java (64-bit) engine.

\section{Statistical analysis}

One way ANOVA with least significant difference (LSD) Post Hoc test was performed. Data expressed as means \pm SE. Values are expressed as mean $\pm \mathrm{SE}, * P<0.001 ; * * P<0.01$ when compared with control.

\section{Results}

\section{Physiological parameters}

Rats injected with $\mathrm{CCl}_{4}$ showed a highly significant increase in ALT activity $(<0.001)$ in $\mathrm{CCl}_{4}$ group. Treatment with silymarin, beet slightly decreased the ALT activity comparing with $\mathrm{CCl}_{4}$ group. Treatment with a combination of silymarin and beet significantly $(<0.05)$ decreased the ALT activity than that of $\mathrm{CCl}_{4}$ group. Also, serum AST activity showed a highly significant increase $(<0.001)$ in $\mathrm{CCl}_{4}$ group and treatment with silymarin significantly $(<0.05)$ decreased the AST activity than that of $\mathrm{CCl}_{4}$ group. Treatment with beet slightly decreased the AST activity, while treatment with a combination of silymarin and beet significantly decreased the AST activity comparing with $\mathrm{CCl}_{4}$ group. The mean serum ALP activity is significantly increased $(<0.001)$ in $\mathrm{CCl}_{4}$ group. Also treatment with silymarin, beet or a combination of silymarin and beet slightly decrease the ALP activity than that of $\mathrm{CCl}_{4}$ group. The mean serum GGT activity showed highly significant increase $(<0.001)$ in $\mathrm{CCl}_{4}$ group. Treatment with silymarin significantly decreased the GGT activity than that of $\mathrm{CCl}_{4}$ group. Treatment with beet significantly decreased the GGT activity. Also, treatment with a combination of silymarin and beet significantly $(<0.05)$ decreased the GGT activity comparing with $\mathrm{CCl}_{4}$ group. The mean levels of GGT activity in rats treated with silymarin, beet or a combination almost reached the levels of normal and vehicle groups, these results are represented in Table 1.

Rats injected with $\mathrm{CCl}_{4}$ shows a highly significant increase in collagen IV, hydroxyproline and image analysis values. Treatment with beet, silymarin or with a combination of them for a period of 8 weeks significantly restored these values, these results are represented in Table 2 showed that the mean collagen IV levels is significantly increased $(<0.001)$ in $\mathrm{CCl}_{4}$ group. Treatment with silymarin and/or beet slightly decreased the 
collagen IV levels than that of $\mathrm{CCl}_{4}$ group. However the mean levels of collagen IV levels in rats treated with silymarin and/ or beet still higher than the collagen IV levels of normal and vehicle groups. The mean hydroxyproline contents showed significantly increased $(<0.001)$ in $\mathrm{CCl}_{4}$ group. Treatment with silymarin and /or beet slightly decreased the hydroxyproline contents than that of $\mathrm{CCl}_{4}$ group. The mean levels of hydroxyproline contents in rats treated with silymarin and/or still higher than the hydroxyproline contents of normal and vehicle groups.

Table 1. Effect of red beet and silymarin on ALT, AST, GGT and ALP levels of $\mathrm{CCl}_{4}$-induced hepatotoxic rats

\begin{tabular}{lllll}
\hline Groups & ALT & AST & GGT & ALP \\
\hline Normal control & $56.6 \pm 9.53^{\text {cdef }}$ & $64.3 \pm 16.05^{\text {cdef }}$ & $10.4 \pm 5.13^{\mathrm{c}}$ & $176.4 \pm 18.59^{\text {cdef }}$ \\
Vehicle control & $64.0 \pm 15.82^{\text {cdef }}$ & $66.0 \pm 16.54^{\text {cdef }}$ & $8.5 \pm 4.05^{\mathrm{c}}$ & $155.1 \pm 19.57^{\text {cdef }}$ \\
CCl $_{4}$ & $438.8 \pm 17.74^{\text {adfg }}$ & $478.3 \pm 40.83^{\text {abdf }}$ & $52.9 \pm 5.67^{\text {abdef }}$ & $533.7 \pm 51.19^{\text {ab }}$ \\
Silymarin & $375.1 \pm 22.56^{\text {ade }}$ & $190.9 \pm 19.67^{\text {abce }}$ & $14.3 \pm 2.8^{\mathrm{c}}$ & $434.3 \pm 38.16^{\text {ab }}$ \\
Beet & $420.5 \pm 29.49^{\text {abd }}$ & $409.9 \pm 36.85^{\text {abdfg }}$ & $15.7 \pm 3.5^{\mathrm{c}}$ & $513.3 \pm 37.67^{\text {ab }}$ \\
Silymarin + beet & $257.1 \pm 19.6^{\text {abcef }}$ & $168.6 \pm 19.44^{\text {abce }}$ & $14.2 \pm 2.98^{\mathrm{c}}$ & $430.9 \pm 41.87^{\text {ab }}$
\end{tabular}

Values are expressed as mean \pm SE. a, Significant vs normal control. b, Significant vs vehicle control. c, Significant vs $\mathrm{CCl}_{4}$ group. d, Significant vs silymarin group. e, Significant vs beet group. f, Significant vs silymarin + beet group.

Table 2. Effect of red beet and silymarin on collagen IV, hydroxyproline and image analysis (I.A.) values of CCl4-induced hepatotoxic rat tissues.

\begin{tabular}{lcll}
\hline Groups & Collagen IV & Hydroxyproline & I.A. \\
\hline Normal control & $26.6 \pm 6.79^{\text {cdef }}$ & $169.9 \pm 7.58^{\text {cdef }}$ & $0.89 \pm 0.16^{\text {cdef }}$ \\
Vehicle control & $25.6 \pm 6.41^{\text {cdef }}$ & $167.1 \pm 15.78^{\text {cdef }}$ & $0.91 \pm 0.25^{\text {cdef }}$ \\
$\mathrm{CCl}_{4}$ & $119.8 \pm 9.57^{\text {abdf }}$ & $609.7 \pm 51.77^{\text {abdef }}$ & $6.19 \pm 0.61^{\text {abdf }}$ \\
Silymarin & $96.1 \pm 8.38^{\text {abcf }}$ & $379.2 \pm 30.22^{\text {abc }}$ & $4.60 \pm 0.30^{\text {abc }}$ \\
Beet & $110.2 \pm 6.33^{\text {abf }}$ & $419.1 \pm 30.28^{\text {abcf }}$ & $5.30 \pm 0.29^{\text {ab }}$ \\
Silymarin + beet & $65.67 \pm 7.26^{\text {abcde }}$ & $325.0 \pm 26.98^{\text {abce }}$ & $3.80 \pm 0.29^{\text {abc }}$
\end{tabular}

Values are expressed as mean \pm SE. a, Significant vs normal control. b, Significant vs vehicle control. c, Significant vs $\mathrm{CCl}_{4}$ group. d, Significant vs silymarin group. e, Significant vs beet group. f, Significant vs silymarin + beet group.

\section{Histopathological changes}

\section{Haematoxylin and Eosin $(H \& E)$ stain}

The results of histopathological examination of the control liver showed non pathological changes observed in hepatic tissues (Fig. 1). The pathology of hepatic tissues at 8 weeks in $\mathrm{CCl}_{4}$ injected rats showed disturbed liver architecture with cloudy swelling of hepatocytes, fatty changes (degeneration) and portal fibrosis (Fig. 2). The pathology of hepatic tissues at 8 weeks in $\mathrm{CCl}_{4}$ injected rats and treated with beet (Fig. 3) and those of hepatic tissues at 8 weeks in $\mathrm{CCl}_{4}$ injected rats and treated with silymarin (Fig. 4) showed slight disturbed liver architecture with degeneration of hepatocytes, inflammatory infiltration and evident portal fibrosis. The pathology of hepatic tissues at 8 weeks in $\mathrm{CCl}_{4}$ injected rats and treated with beet and silymarin showed mostly normal liver architecture with very minimal portal fibrosis (Fig. 5).

\section{Sirius Red (SR) stain}

Histopathological examination for control group observed normal hepatic tissues (Fig. 6). Rats injected with $\mathrm{CCl}_{4}$ showed fibrosis with evidence of diffuse subsegmentations of the portal lobules (Fig. 7). Rats injected with $\mathrm{CCl}_{4}$ 
and treated with beet (Fig. 8) and those injected with $\mathrm{CCl}_{4}$ and treated with silymarin (Fig. 9) showed evident portal fibrosis. Rats injected with $\mathrm{CCl}_{4}$ and treated with beet and silymarin showed very minimal portal fibrosis (Fig. 10).

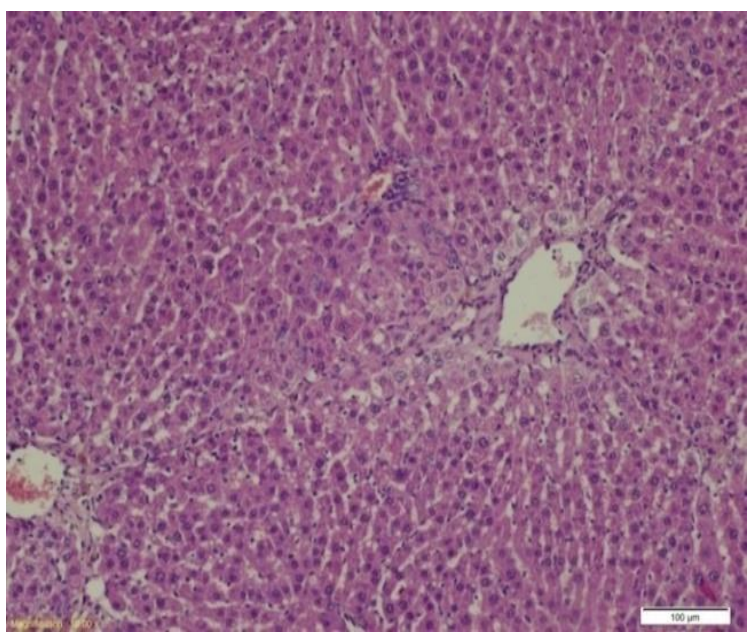

Fig. 1 Histopathological pattern of hepatic tissue in control rats (H\&E, X100).

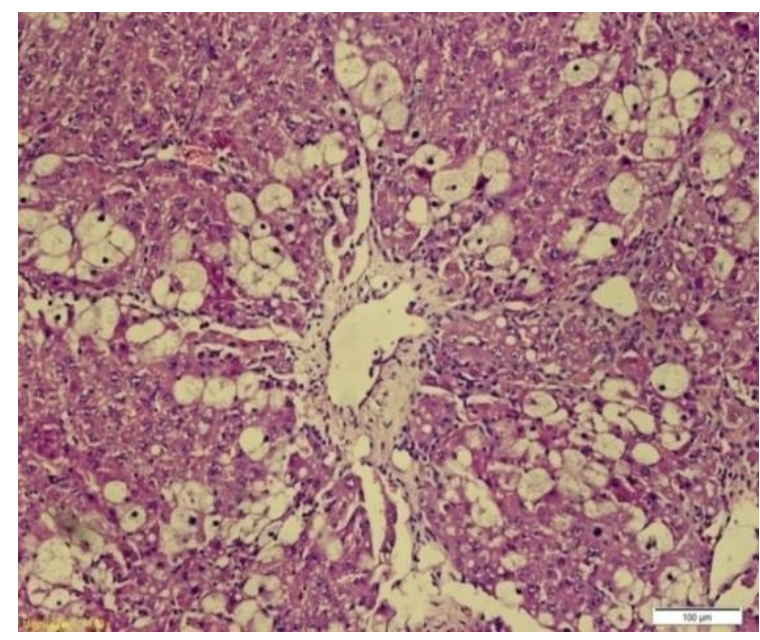

Fig. 2 Histopathological pattern of hepatic tissue at 8 weeks in $\mathrm{CCl}_{4}$ injected rats $(\mathrm{H} \& \mathrm{E}, \mathrm{X} 100)$.

The determination of fibrosis by image analysis software showed that the mean fibrosis values was significantly increased $(<0.001)$ in $\mathrm{CCl}_{4}$ group. Treatment with silymarin, beet slightly decreased the fibrosis values than that of $\mathrm{CCl}_{4}$ group. Treatment with a combination of beet and silymarin was significantly decreased the fibrosis values than that of $\mathrm{CCl}_{4}$ group. The fibrosis values in rats treated with silymarin, beet or with a combination of them still higher than the fibrosis values of normal and vehicle groups Table 2.

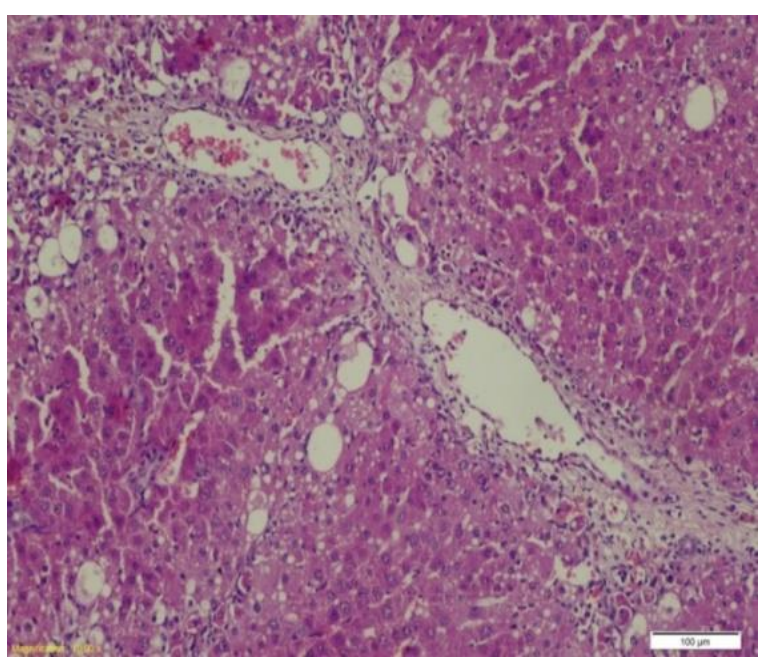

Fig. 3 Histopathological pattern of hepatic tissue at 8 weeks in $\mathrm{CCl}_{4}$ injected rats and treated with beet (H\&E, X100).

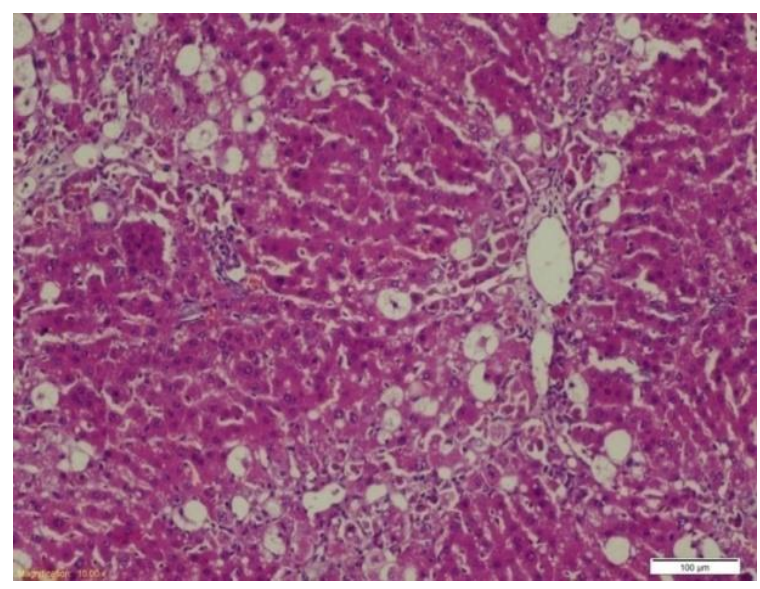

Fig. 4 Histopathological pattern of hepatic tissue at 8 weeks in $\mathrm{CCl}_{4}$ injected rats and treated with silymarin (H\&E, X100).

\section{Discussion}

The liver is generally responsible for detoxifying chemical agents and poisons, whether ingested or inhaled. Pre-existing liver disease may inhibit or alter detoxification processes and thus increase the toxic effects of these agents. Additionally, exposure to chemicals or toxins may directly affect the liver, ranging from mild dysfunction to 
severe and life-threatening damage (Jains, 2007). Liver injury induced by carbon tetrachloride is the best characterized system of xenobioticinduced hepatotoxicity and is a commonly used model for screening the hepatoprotective activity of natural compounds (Recnagel, 1983).

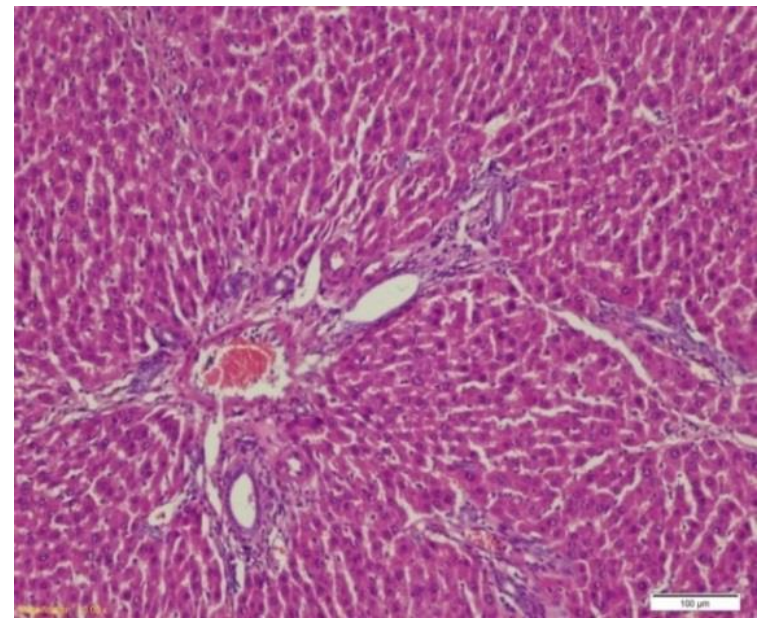

Fig. 5 Histopathological pattern of hepatic tissue at 8 weeks in $\mathrm{CCl}_{4}$ injected rats and treated with beet and silymarin (H\&E, X100).

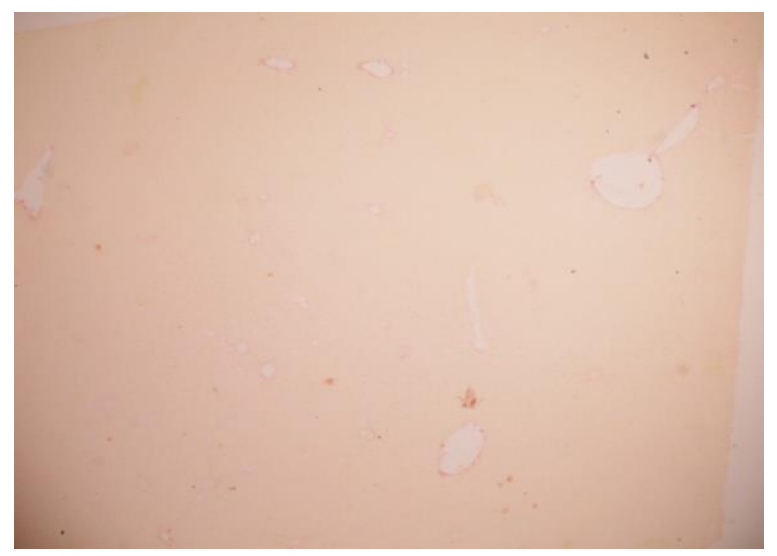

Fig. 6 Histopathological examination in liver section of control rats (SR, X100).

The hepatotoxic effect of $\mathrm{CCl}_{4}$ is a result of its reductive dehalogenation by cytochrome enzyme (CYP2E1) into the highly reactive trichloromethyl and trichloromethylperoxy free radicals. Both radicals form adducts with cellular macromolecules and abstract hydrogen from different molecules, thus initiating oxidation of lipids, proteins, and DNA (Recnagel, 1983).

Although $\mathrm{CCl}_{4}$ is not directly mutagenic, it can exert genotoxic effects under highly cytotoxic conditions through oxidative damage or endonuclease activation combined with sustained regeneration and increased cellular proliferation. $\mathrm{CCl}_{4}$ has been shown to induce hepatocellular carcinomas in rodents by oral inhalation and parenteral exposure (Manibusan et al., 2007). The International Agency for Research on Cancer (IARC) was classified $\mathrm{CCl}_{4}$ as a potential human carcinogen (IARC 1999). As oxidative stress plays a central role in $N$-nitrosodiethylamine (NDEA) and $\mathrm{CCl}_{4}$-induced toxicity, the use of phytochemicals with antioxidant activity can offer protection against this oxidative damage. In view of the findings that NDEA and $\mathrm{CCl}_{4}$ are capable of inducing oxidative damage and share common metabolic systems involved in their activation. In this study, data coming from the model of liver injury proved that, the intraperitonealy injected rats by $\mathrm{CCl}_{4}$ in olive oil $\left(0.5 \mathrm{ml} \mathrm{Kg}{ }^{-1}\right.$ of body weight $) 2$ times a week for 8 weeks, exhibited liver injury and parallelism between both biochemical and histochemical parameters, which are in agreement with the findings obtained by Theocharis et al. (2001) and Ko and Lim (2006).

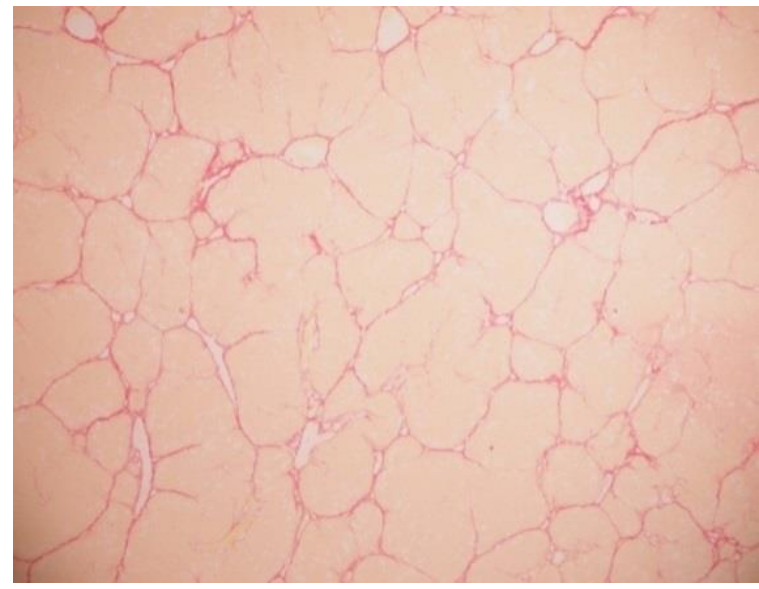

Fig. 7 Histopathological examination in liver section of $\mathrm{CCl}_{4}$ injected rats (SR, X100).

Beta vulgaris has been used in folk medicine to treat a wide variety of ailments like fever, constipation, cancer and diabetes. Modern research is investigating in further detail how beet extracts could be used to protect normal and diabetic liver, however no systemic scientific study is available on its effect as hepatoprotective agent. Phytochemical studies of Beta vulgaris root reveal the presence of flavonoids, carbohydrate, betain, neobetain and anthocyanin 
pigments (Pal et al., 2010).

Data obtained in this study showed significant elevation in serum levels of aminotransferases enzymes (AST, ALT), ALP and GGT in $\mathrm{CC}_{4}$ intoxicated rats compared with control group. The high levels of liver enzymes are positively correlated with the presence of histopathological changes evidenced as week lymphocyte infiltration; moderate steatosis and portal fibrosis in tissues of $\mathrm{CCl}_{4}$ intoxicated rats. This elevation may be attributed to hepatocellular damage by hepatotoxic agents used in this study. A concentration gradient, which is dependent on normal cellular metabolism for its maintenance, exists for enzymes between the hepatocyte and the sinusoidal space. On damage to the process of cellular energy production, permeability of the hepatocyte membrane increases and cytosolic isoenzymes of the aminotransferases (ALT and AST) spill into the sinsusoids and then to the peripheral blood. Permeability of mitochondrial membranes may also increase and mitochondrial isoenzymes are then released, as described by William et al. (1997). There is an agreement between the data obtained in this study and those obtained by Ko and Lim (2006) and Rasool et al. (2014) They detected a marked elevation in aminotransferases enzymes (AST and ALT) in the serum of the $\mathrm{CC1}_{4}$ intoxicated rats.

The present study revealed that, the levels of collagen IV in serum of $\mathrm{CCl}_{4}$ intoxicated rats was significantly increased as compared to control group. The increased in serum collagen activity are positively correlated with the presence of histopathological fibrosis in tissues of $\mathrm{CC}_{4}$ intoxicated rats. These results agree with the results of Maruysma et al. (1982) who reported that, the activities of the enzymes that can degrade the extracellular matrix (ECM) were increased with fibrosis. However, hepatic collagenase activities against collagens type I and IV were diminished once liver cirrhosis was established (Miura, 1985).

From the results of this study, it was found that hepatic hydroxyproline concentration was very significantly increased in the liver of the $\mathrm{CCl}_{4}$ intoxicated rats than that of non-intoxicated group. The increased levels of hepatic hydroxyproline concentration are positively correlated with the presence of histopathological marker as portal fibrosis in the tissues of $\mathrm{CC}_{4}$ intoxicated rats. Similar observations have been reported previously (Jeong et al., 2005).

The histopathological results of Haematoxylin $\&$ Eosin stained tissues; showed that the structure of lobules was destroyed and pseudolobules formed, moderate steatosis and week inflammation in $\mathrm{CCl}_{4}$-induced liver injury rats.

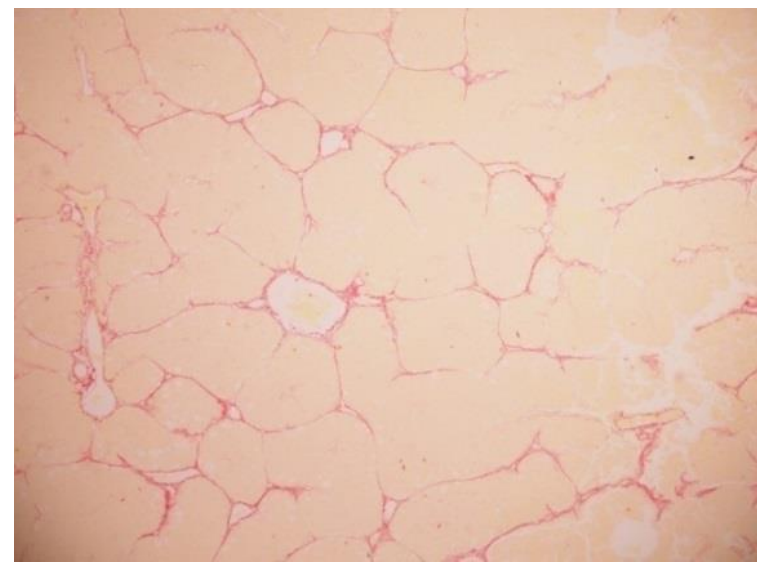

Fig. 8 Histopathological examination in liver section of $\mathrm{CCl}_{4}$ injected rats and treated with beet (SR, $\mathrm{X} 100)$.

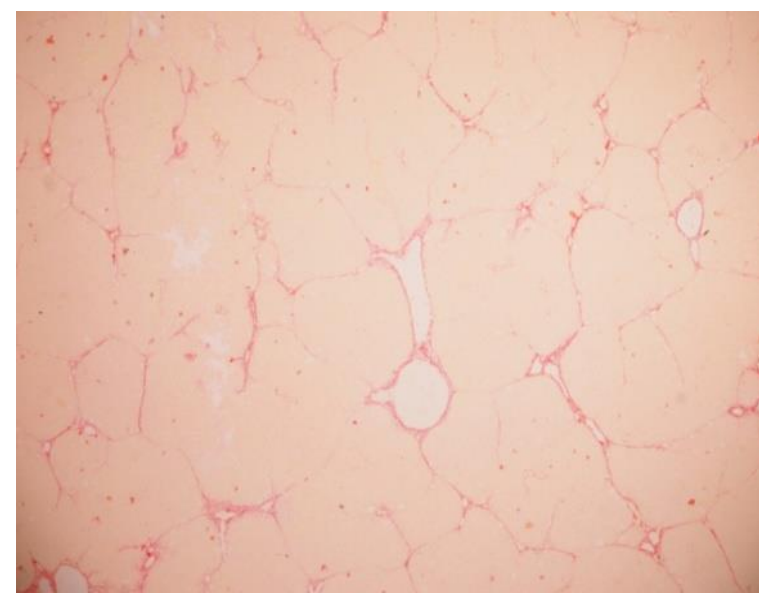

Fig. 9 Histopathological examination in liver section of $\mathrm{CCl}_{4}$ injected rats and treated with silymarin (SR, $\mathrm{X} 100)$.

The administration of $\mathrm{CC}_{4}$ in rats caused severe liver histopathological injury, as confirmed by significant increased activities of serum hepatic enzymes (ALT, AST, ALP and GGT). These results are in agreement with Theocharis et al. (2001) and Zasshi (2006) who demonstrated steatosis and inflammation in hepatic tissues of $\mathrm{CCl}_{4}$-induced liver injury rats compared to non-intoxicated rats.

In the current study, the hepatic tissues showed weak fibrosis in rats exposed to $\mathrm{CC}_{4}$. These results are correlated directly with significant increased concentration of hepatic 
hydroxyproline and serum collagen IV level. These data are better than that obtained by Weng et al. (2001) who found that hepatic fibrosis stage was obtained at the fourth week after intraperitoneal administration of $\mathrm{CCl}_{4}$ dissolved in olive oil.

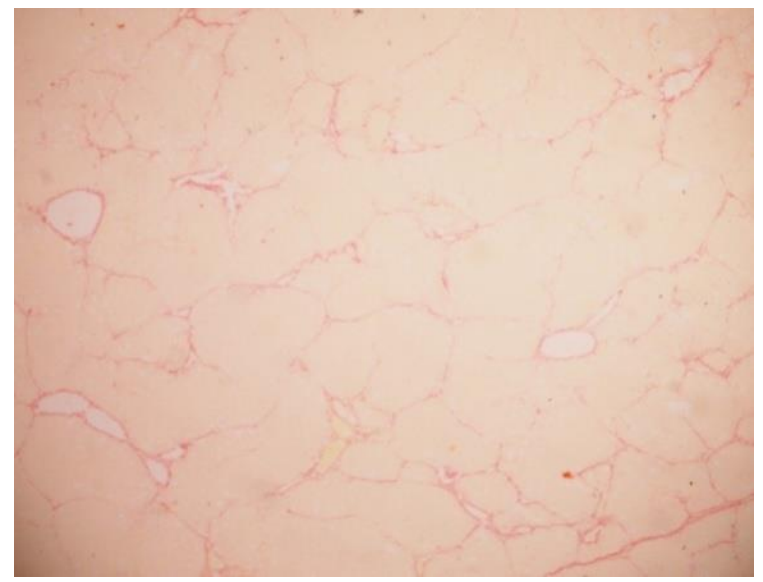

Fig. 10 Histopathological examination in liver section of $\mathrm{CCl}_{4}$ injected rats and treated with beet and silymarin(SR, X100).

In the light of these results, one may conclude that hydroxyproline concentration was increased after $\mathrm{CCl}_{4}$ intoxication and the same trend of changes was noted in collagen level.. These results indicate that hepatic hydroxyproline concentration is directly correlated with collagen level. Also there is a positive correlation between these results and pathological fibrosis markers.

In the current study, a significant positive correlation was also found between hydroxyproline, serum collagen activity and fibrosis score measured by image analysis in $\mathrm{CCl}_{4}$ induced liver injury groups. This good correlation demonstrates that, fibrosis in the liver can be determined by using the new noninvasive fibrosis index without making liver histochemical investigation. Therefore, this new noninvasive fibrosis index may be used as a useful biomarker in the diagnosis and follow up patients with liver diseases.

\section{Conclusions}

In conclusion, the present results revealed that $\mathrm{CCl}_{4}$ induced liver damage may be modulated by dietary supplementation of fresh Juice from red beet root, or silymarin. However, the best effects observed were in rats treated with a combination of red beet root juice and silymarin.

\section{References}

Agarwal M, Srivastava VK, Saxena KK and Kumar A (2006) Hepatoprotective activity of Beta Vulgaris against $\mathrm{CCl}_{4}$-induced hepatic injury in rats. Fitoterapia, 77, 91-93.

Al-Rasheed NM, Al-Rasheed NM, Faddah LM, Mohamed AM, Mohammad RA and Al-Amin M (2014) Potential impact of silymarin in combination with chlorogenic acid and/or melatonin in combating cardiomyopathy induced by carbon tetrachloride. Saudi Journal of Biological Sciences, 21, 265-274.

Balistreri WF and Rej R (1994) Liver function. In:Titz. Text Book of Clinical Chemistry. Burtis, C.A. and Ashwood, E.R. (eds), W.B. Saunders Company, U.S.A., $2^{\text {nd }}$ Ed. P. 449-1460.

Deep G, Oberlies NH, Kroll DJ and Agarwal R (2007) Isosilybin $\mathrm{B}$ and isosilybin $\mathrm{A}$ inhibit growth, induce G1 arrest and cause apoptosis in human prostate cancer $\mathrm{LNCaP}$ and $22 \mathrm{Rv} 1$ cells. Carcinogenesis, 28:1533-1542.

EL-Aaser AA and EL-Merzabani MM (1975) Simultaneous determination of 5'-nucleotidase and alkaline activities in serum. Z. Klin. Chem. Klin. Biochem., 13:453.

IARC (1999) Monographs on the Evaluation of Carcinogenic Risks to Humans; International Agency for Research on Cancer : Lyon, France, Vol. 71

Jains A (2007) The European Association for the Study of the Liver. 42nd European Association for the Study of the Liver Diseases, Barcelona, Spain, April 11-15.

Jeong DH, Lee GP, Jeong WI, Do SH , Yang HJ, Yuan DW, Park HY, Kim KJ and Jeong KS (2005) Alterations of mast cells and TGF-al on the silymarin treatment for $\mathrm{CCl}_{4}$-induced hepatic fibrosis. World J. Gastroenterol., 11: 1141-1148.

Junqueira LCU, Bignolas G and Brentani RR (1979) Picrosirius staining plus polarization microscopy, a specific method for collagen detection in tissue sections. Histochem J., 11: 447-455.

Kanner J, Harel S, Granit R and Betalains H (2001) A new class of dietary cationized antioxidants. J. Agric. Food Chem.,49, 5178- 5185.

Kapadia GJ, Tokuda H, Konoshima T, Nishino H (1996) Chemoprevention of lung and skin cancer by Beta Vulgaris (beet) root extract. Cancer Lett., 100, 211-214.

Kapadia GJ, Azuine MA, Sridhar R, Okuda Y, Tsuruta A, Ichiishi E, Mukainake T, Takasaki M, Konoshima T, Nishino H and Tokuda H (2003) Chemoprevention of DMBA-induced UV-B promoted, NOR-1-induced TPA promoted skin carcinogenesis, and DEN-induced phenobarbital 
promoted liver tumors in mice by extract of beet root. Pharmacol. Res., 47, 141-148.

Karimi G, Vahabzadeh M, Lari P, Rashedinia M, Moshiri M (2011) Silymarin, a promising pharmacological agent for treatment of diseases. Iran J. Basic Med. Sci.,14:308-317.

Ko JH and Lim KT (2006) Glycoprotein isolated from Ulmusdavidiana Nakai protects against carbon tetrachloride-induced liver injury in the mouse. J. Pharmacol. Sci., 101: 205-213.

Laitinen O, Kivirikko KI and Prockop DJ (1974) Clinical application of urinary hydroxyproline determination. Acta Med. Scand. Supple., 577: 485-490.

Loguercio C and Festi D (2013) Silybin and the liver: from basic research to clinical practice. World J. Gastroenterol, 17: 2288-2301.

Madrigal-Santillan E, Madrigal-Bujaidar E, CruzJaime S, Valadez-Vega MC, Sumaya-Martinez MT, Perez-Avila KG and Morales-Gonzalez JA( 2013) The Chemoprevention of Chronic Degenerative Disease Through Dietary Antioxidants: Progress, Promise and Evidences. In: Morales-Gonzalez JA, editor. Oxidative stress and chronic degenerative diseases-A role for antioxidants. Rijeka: Croatia, p. 155-185.

Mandl I, MacLennan JD and Hawes EL (1953) Isolation and characterization of proteinase and collagenase from $\mathrm{Cl}$. Histolyticum. J. Clin. Invest., 32:1323-1327.

Manibusan MK, Odin M and Eastmond DA( 2007) Postulated carbon tetrachloride mode of action: a review. J. Environ. Sci. Health, 25, 185-209.

Maruysma K, Feinmanfainsilber Z, Nakano M, Okazaki I and Lieber CS (1982) Mammalian collagenase increases in early alchoholic liver disease and diseases with cirrhosis. Life Sci., 30: 1379-1384.

Mazaheri S, Moaeidi B A and Nematbakhsh M (2014) Protective Role of Silymarin and Deferoxamine against Iron Dextran-Induced Renal Iron Deposition in Male Rats," and "Co-Administration of Silymarin and Deferoxamine against Kidney, Liver and Heart Iron Deposition in Male Iron Overload Rat Model". Int. J. Prev. Med, 5(6): 800801.

Miura M (1985) Prolyl hydroxyllase activity and collagenase activity in the liver tissue of nonalcoholic chronic liver diseases. Jpn. J. Gastroenterology, 82: 1551-1558.

Moussa TA, EL-Aaser AA and EL-Banhawy MA (1984) Principles and practice of histochemistry. Dar Al-Mssref, Cairo, Egypt, P. 7-9.

Moussavian SN, Becker RC and Piepmeyer JL (1985) Serum gamma-glutamyl transpeptidase and chorinc alcoholism: Influence of alcohol ingestion and liver disease. Dig. Dis. Sci., 30: 211-214.

Pal R, Girhepunje K, Gevariya H and Thirumoorthy N (2010) Hepatoprotective activity of Beta vulgaris against $\mathrm{CCl}_{4}$ induced acute hepatotoxicity in rats. Archives of Applied Science Res, 2 (1): 14-18.

Rasband WS (1997-2014) Imagej, U.S, National Institutes of Health http: //imagej.nih.gov/ij/

Rasool M, Iqbal J, Malik A, Ramzan HS, Qureshi MS, Asif M, Qazi MH, Kamal MA, Chaudhary AA, Al-Qahtani MH, Gan SH and Karim S (2014) Hepatoprotective Effects of Silybum marianum (Silymarin) and Glycyrrhizaglabra (Glycyrrhizin) in Combination: A Possible Synergy. EvidenceBased Complementary and Alternative Medicine, 2014: 1-9.

Recnagel RO (1983) Carbon tetrachloride hepatotoxicity:status quo and future prospects. Trends Pharmacol Sci,4, 129-131.

Reitman A and Frankel S (1957) Determination of serum glutamic oxaloacetic and glutamic pyruvic transaminase. Am. J. Clin. Path., 28:56-60.

Su CH, Chen LJ, Liao JF and Cheng JT (2013) Dual effects of silymarin on nasopharyngeal carcinoma cells (NPC-TW01). Forsch Komplement med, 20:261-266.

Szaefer H, Krajka-Kuzniak V, Ignatowicz E, Adamska T, Baer-Dubowska W (2014) Evaluation of the effect of beetroot juice on DMBA-induced damage in liver and mammary gland of female SpragueDawley rats. Phytother Res, 28(1):55-61.

Theocharis SE, Margeli AP, Skaltsas SD, Spiliopooulou CA and Koutselinis AS (2001) Induction of metallothionein in the liver of carbon tetrachloride intoxicated rats: an immunohistochemical study. Toxicology, 161: 129-138.

Tsuchiya S, TsuKamoto Y, Tair E and LaMarre J (2007) Involvement of transforming growth factorbeta in the expression of glycerin, a cell adhesion molecule, in the regeneration of hepatocytes. Int. J. Mol., 19: 381-386.

Vazquez-Medina JP, Zenteno-Savin T, Forman $\mathrm{Hj}$, Crocker DE and Ortiz RM (2011) Prolonged fasting increases glutathione biosynthesis in post weaned northern elephant seals. J. Exp. Biol., 214: 1294 - 1299.

Weng HL, Cai WM and Liu RH (2001) Animal experiment and clinical study of effect of gammainterferon on hepatic fibrosis. World $\mathrm{J}$. Gastroenterology, 7: 42-48.

Whitby LG, Smith AF and Beckett GJ (1988) Lecture Notes on Clinical Chemistry. Blackwell Scientific Publications. P. 136-140.

William F, Balistreri MD and Robert R (1997) Liver function. In:"Tietz Fundamentals of Clinical Chemistry". Burtis, C.A. and Ash wood, E.R. (eds). U.S.A. W.B. Saunders Company, P. 539568.

Zasshi Y (2006) Learning toxicology from carbon tetrachloride-induced hepatotoxicity. The Pharmaceutical Society of Japan, 126: 885-899. 
الهدف من هذا البحث هو دراسة تأثير كل من عصير جذور البنجر (الشمندر) والسليمارين على حماية الكبا

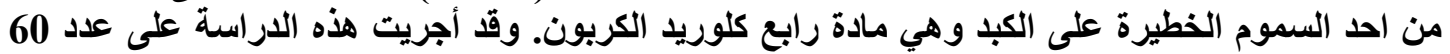

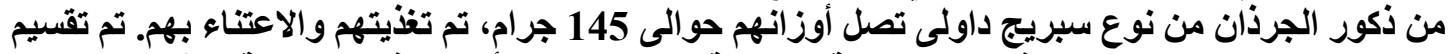

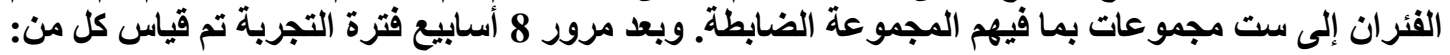

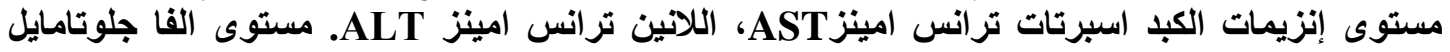

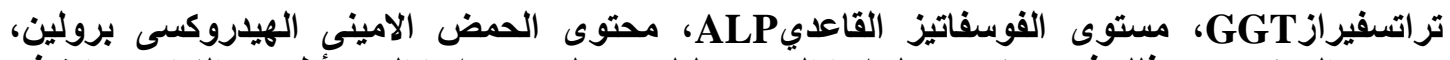

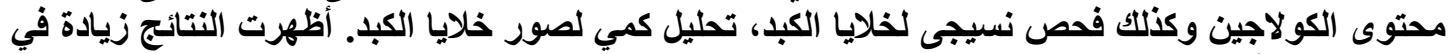

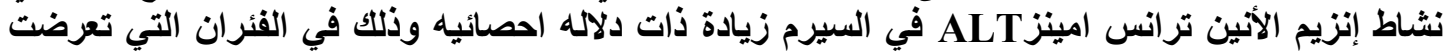

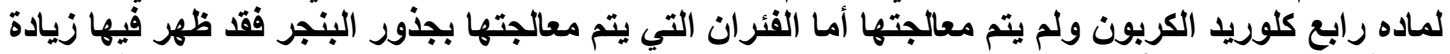

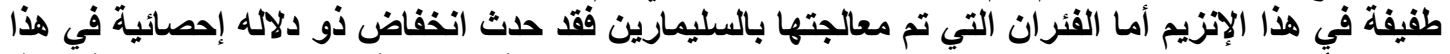

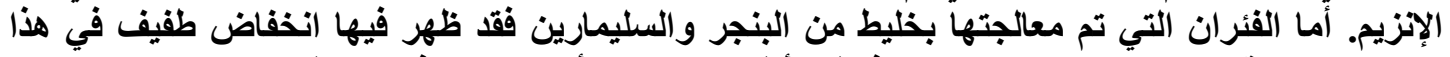

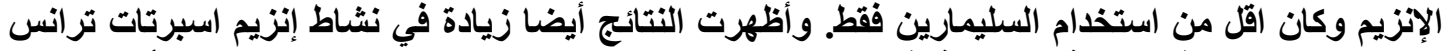

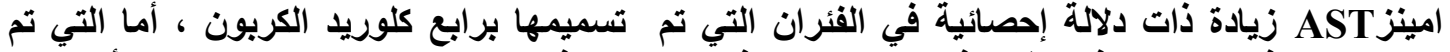

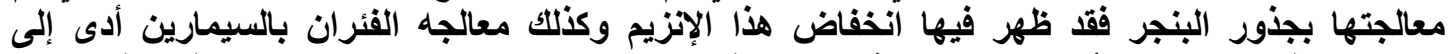

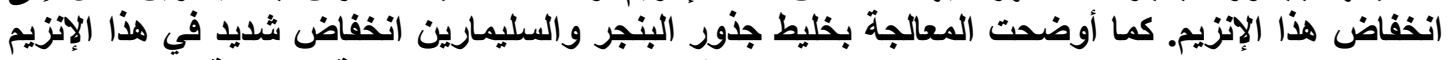

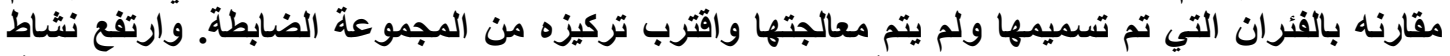

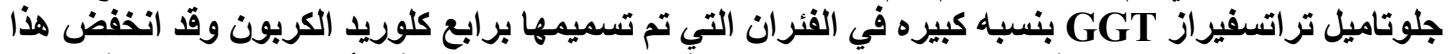

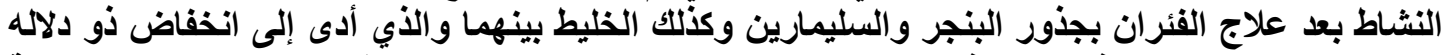

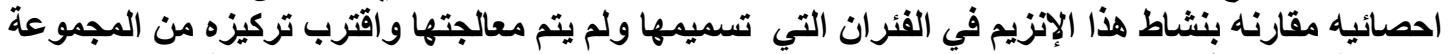

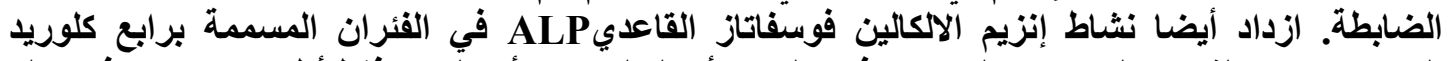

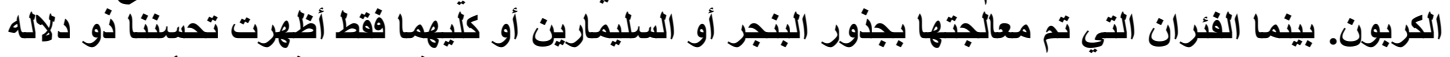

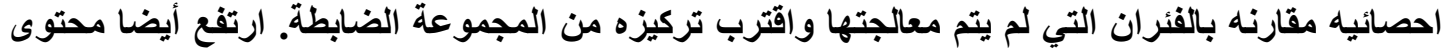

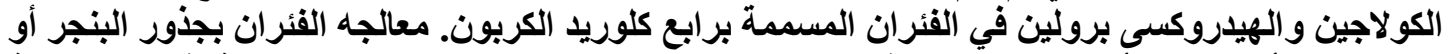

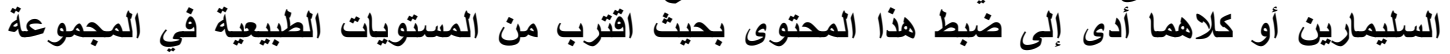

الضابطة.

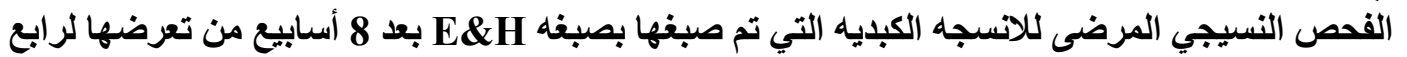

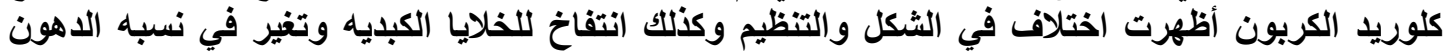

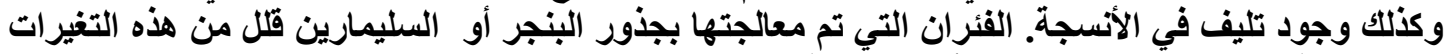

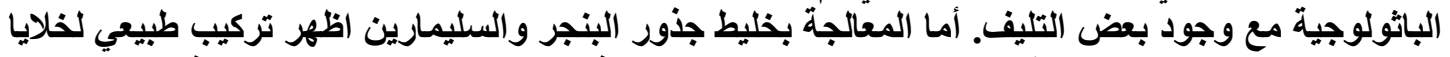

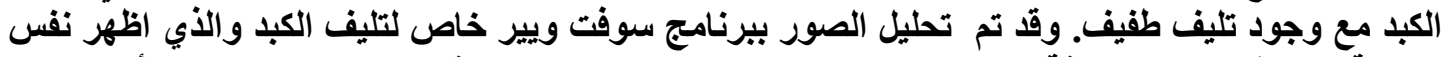

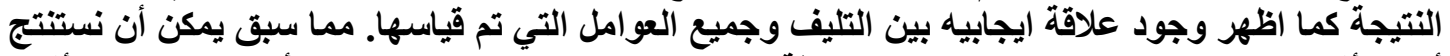

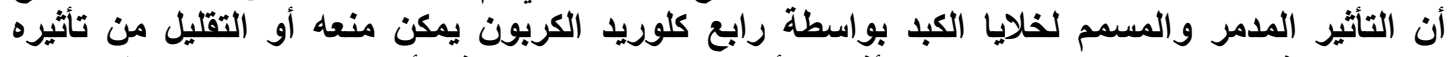

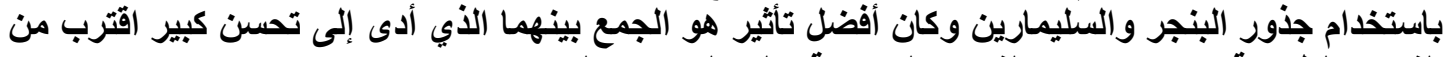

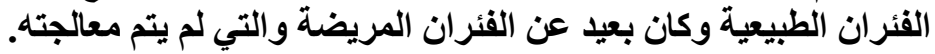

